\title{
Early progressive changes in tissue viability in the seated spinal cord injured subject
}

\author{
KM Bogie ${ }^{1}$, I Nuseibeh ${ }^{1}$ and DL Bader ${ }^{1,2}$ \\ ${ }^{1}$ National Spinal Injuries Centre, Stoke Mandeville Hospital, Aylesbury; ${ }^{2}$ IRC in Biomedical Materials and \\ Department of Materials, Queen Mary and Westfield College, University of London, London, UK
}

\begin{abstract}
The patient with spinal cord injury is at high risk of tissue breakdown at all times due to a number of adverse factors, such as reduced mobility and anaesthesia. It is therefore essential that each patient is prescribed appropriate support media during initial rehabilitation. In this study, the effectiveness of prescribed wheelchair cushions has been assessed in terms of tissue response at the ischial tuberosities. A total of 42 subjects who had sustained traumatic spinal cord injury within 1 year were monitored on at least two occasions during initial rehabilitation. Changes in transcutaneous gas response $\left(\mathrm{T}_{\mathrm{c}} \mathrm{PO}_{2}\right.$ and $\left.\mathrm{T}_{\mathrm{c}} \mathrm{PCO}_{2}\right)$ were monitored concurrently with regional interface pressures. A series of six transcutaneous gas variables were established, as markers of tissue viability. Non-parametric statistical analyses revealed some significant correlations between these variables. The results of this study also indicate that (1) spinal cord injury subjects with lesions below T6 show a progressive decrease in ability to maintain blood flow in sitting on prescribed support cushions and (2) SCI subjects with lesions above T6 show a progressive improvement in tissue viability status at the seating support interface. Therefore results imply that paraplegics are at a potentially higher risk of tissue breakdown than tetraplegics and thus require effective support cushions with strict adherence to a pressure relief regime.
\end{abstract}

Keywords: pressure sores; paraplegia; tissue viability; cushion; transcutaneous gas tension

\section{Introduction}

The development of pressure sores is one of the most common factors causing delay in the rapid rehabilitation of the spinal cord injury (SCI) patient. In addition, such a patient remains at risk in the future of developing a pressure sore at all times following injury, as is illustrated by a reported incidence of $11 \%$ of the total number of cases re-admitted to a spinal unit over a 6 year period. ${ }^{1}$ Forty seven per cent of these sores occurred at either the ischial tuberosities or the sacrum and thus may be considered likely to have been initiated in the sitting posture. It has also been reported that SCI patients readmitted with pressure sores will be hospitalised for a period ranging from 7 days to 1 year, with a mean stay of 3 months. ${ }^{2}$ The financial implications are also significant. The cost of healing a grade IV sore, ie one with full thickness breakdown of the soft tissues with involvement of the underlying bone, was estimated to be $£ 25,000$ in an elderly subject. ${ }^{3}$ In addition, financial compensation may be ordered by the courts where patients have been proved to develop pressure sores during their hospital stay.

Any rehabilitation programme must include the education of every SCI patient in their personal

Correspondence: Dr Dan Bader, IRC in Biomedical Materials, Queen Mary and Westfield College, Mile End Road, London, E1 4NS, UK responsibility for prevention of tissue breakdown, by means of personal skin care, regular inspection of susceptible areas and appropriate pressure relief regimes together with maintenance and the correct use of suitable equipment. Spinal cord injury patients are generally instructed to perform pressure relief every 15 minutes in the sitting position. ${ }^{4}$ Normal procedures for pressure relief include lifting the whole ischial region clear of the seating surface for about 30 seconds or leaning forward or from side to side as far as possible for 1-2 min. It is also essential for health professionals to prescribe the necessary support media, including seating support systems, most appropriate to the needs of each individual. Cushion prescription options for the individual SCI patient at the National Spinal Injuries Centre include the use of foam, gel and air as the support media.

\section{Tissue viability}

Tissue breakdown leading to pressure sores will occur as the direct result of compromise to the integrity of the regional capillary blood supply and lymphatic drainage. Although many factors will adversely affect tissue viability, the primary cause of pressure sores is generally considered to be externally applied pressure leading to local capillary occlusion and thus to pro- 
longed tissue ischaemia. The nature of the local soft tissues will influence their response to applied pressures. Thus areas with high compressive stiffness will develop greater interstitial stresses under the same applied pressure than areas where there are significant subcutaneous tissues to provide viscoelastic support. ${ }^{5}$ Thus, tissue breakdown is more likely to occur in regions with minimal soft tissue over bony prominences, such as the sacrum and the ischial tuberosities.

The Oxford pressure monitor employs pneumatic principles in order to measure the interface pressures across an area covered by a 12 cell matrix, each cell having a $20 \mathrm{~mm}$ diameter. ${ }^{6}$ However, the measurement of pressure alone is not sufficient to alert the clinician to potential areas of tissue breakdown during the rehabilitation of SCI patients. As with other susceptible patient groups, the measurement of tissue viability is required, which is dependent upon the adequate supply of nutrients from the blood circulation. Non-invasive assessment of transcutaneous gas tensions provides an objective measure of tissue viability. Transcutaneous oxygen tension $\left(\mathrm{T}_{\mathrm{c}} \mathrm{PO}_{2}\right)$ in the unloaded soft tissue of healthy subjects has been found to be in excess of $10.7 \mathrm{kPa}(80 \mathrm{~mm} \mathrm{Hg}) .^{7}$ Prolonged loading at bony prominences has been shown to reduce the $\mathrm{T}_{c} \mathrm{PO}_{2}$ levels in a heterogeneous group of debilitated subjects, ${ }^{8,9}$ although there is no current data concerning the survival of soft tissues at these reduced values. However an upper threshold value of $4.0 \mathrm{kPa}$ $(30 \mathrm{~mm} \mathrm{Hg})$, representing a $60 \%$ reduction of the normal value, has been suggested in a recent study by the present authors. ${ }^{10}$ It was considered that the risk to tissue viability would significantly increase as $\mathrm{T}_{c} \mathrm{PO}_{2}$ levels were reduced below this threshold value. This study assessed the changes in transcutaneous gas tensions over the loaded sacrum during the acute phase of spinal cord injury. The results indicated that the possibility of tissue breakdown, as evidenced by the compromised levels of $\mathrm{T}_{c} \mathrm{PO}_{2}$ and $\mathrm{T}_{\mathrm{c}} \mathrm{PCO}_{2}$, was constant throughout the 3 months following injury.

In the current study the combined measurement of transcutaneous gas tensions and interface pressures have been employed to assess the tissue viability in a group of SCI subjects undergoing rehabilitation within 1 year of injury. In particular, progressive changes in tissue response to conditions at the seating interface were monitored to evaluate cushion performance and predisposition to impaired viability.

\section{Methods and materials}

\section{Test equipment}

The transcutaneous oxygen tension $\left(\mathrm{T}_{\mathrm{c}} \mathrm{PO}_{2}\right)$ and transcutaneous carbon dioxide tension $\left(\mathrm{T}_{\mathrm{c}} \mathrm{PCO}_{2}\right)$ were measured using a Radiometer TCM3 monitor connected to a TCR3 chart recorder (Radiometer $\mathrm{A} / \mathrm{S}$, Copenhagen, Denmark). The combined oxygen and carbon dioxide electrode (Radiometer, model D841) was calibrated using gas containing $20.9 \% \mathrm{O}_{2}$ and $5 \%$ $\mathrm{CO}_{2}$ in nitrogen. The temperature control system of the monitor was set at $43^{\circ} \mathrm{C}$. The variation in room temperature over the course of each assessment was $24^{\circ} \pm 2{ }^{\circ} \mathrm{C}$.

Pressures at the interface between the body tissues and the support cushion were measured using the Oxford pressure monitor (Talley Group Ltd, Romsey, Hampshire, UK).

\section{Subjects}

Series of two or more assessments were obtained for 42 subjects who had sustained traumatic spinal cord injury within 1 year. Subjects were classified according to level of lesion. Twenty three subjects had sustained lesions above T6; six females and 17 males, aged 17-60 years, mean 26.1 years. Nineteen subjects had sustained lesions below T6; eight females and 11 males, aged $16-57$ years, mean 27.5 years.

Prescription of support cushions was carried out in a routine manner by the physiotherapy department. This decision was based on the level of injury, postural and functional requirements and subject susceptibility to tissue breakdown. The majority of subjects were initially supplied with a 4" Dunlopillo foam cushion (Dunlopillo Ltd, Harrogate, North Yorkshire, UK). However those subjects with complete tetraplegia were generally prescribed a Sumed gel cushion (Sumed International Ltd, Banbury, Oxfordshire, UK). Subjects who had a history of tissue breakdown or persistent erythema were prescribed a Jay cushion (Jay Medical Ltd, Boulder, Colorado, USA). In this study the prescribed support cushion was used for the assessment of each subject. The distribution of cushions in each subject group is shown in Table 1. The condition of each cushion was examined throughout the study.

\section{Test procedure}

Ethical approval for this study was obtained from the Aylesbury Vale Health Authority Research Ethical Committee. Subjects with a history of skin marking at a particular ischial site were monitored at that site. However, in subjects with no history of marking, serial assessments were made at one or both ischial tuberosities; in the latter case the choice of site was randomly allocated at the initial assessment.

In order to approximate the angulation of the lower limbs in sitting, the subject was placed in a side-lying position on a bed or plinth, with hips and knees flexed to $90^{\circ}$. The ischial tuberosity to be monitored was palpated and a fixation ring located over the bony

Table 1 Distribution of support cushions prescribed to each subject group

\begin{tabular}{lcc}
\hline Cushion type & $\begin{array}{c}\text { Group I } \\
\text { (above T6) } \\
n=23\end{array}$ & $\begin{array}{c}\text { Group II } \\
\text { (below T6) } \\
n=19\end{array}$ \\
\hline 4" Dunlopillo foam & $7(30 \%)$ & $13(68 \%)$ \\
Sumed & $6(26 \%)$ & $2(11 \%)$ \\
Jay Medical/Active & $10(44 \%)$ & $4(21 \%)$ \\
\hline
\end{tabular}


landmark, the central region was filled with contact liquid and the electrode securely attached. A standard $4 \times 3$ cell matrix of the Oxford pressure monitor was split in half to form two six-cell matrices. These were located over the ischial region either side of the transcutaneous gas electrode. After a 5-10 min period of equilibration with the electrode unloaded, the subject was carefully transferred to the seated posture. The position of the electrode was checked to ensure that it had remained located over the ischial tuberosity and the assessment commenced.

The experimental procedure followed the guidelines indicated in Figure 1, for a total assessment period of 20-30 min. Following the equilibration period, the subject was asked to perform their usual pressure relief procedure as described. If the procedural guidelines indicated that a prolonged pressure relief was required, subjects were asked either to lift themselves clear for up to $3 \mathrm{~min}$ or lean forwards for the same period. Subsequent assessments were repeated at 2-4 week intervals, where practical, up to discharge.

\section{Data analysis}

The efficiency of a prescribed support cushion can be related to the levels of transcutaneous oxygen and carbon dioxide tensions maintained at the seating interface under the prevailing active pressure relief regime of the subject. Transcutaneous gas levels were continuously monitored during each assessment and displayed on a graphical output. In order to evaluate $\mathrm{T}_{\mathrm{c}} \mathrm{PO}_{2}$ and $\mathrm{T}_{\mathrm{c}} \mathrm{PCO}_{2}$ distributions, an identical procedure was adopted to that in the previous study involving the acute SCI subject (10). Thus a distribution of $\mathrm{T}_{\mathrm{c}} \mathrm{PO}_{2}$ was established, as indicated in diagrammatic form in Figure 2a, from the three variables:

LTO The percentage assessment time that the $\mathrm{T}_{\mathrm{c}} \mathrm{PO}_{2}$ level was less than $10 \mathrm{mmHg}$

ITO The percentage assessment time that the $\mathrm{T}_{\mathrm{c}} \mathrm{PO}_{2}$ level was between $10 \mathrm{mmHg}$ and $30 \mathrm{mmHg}$

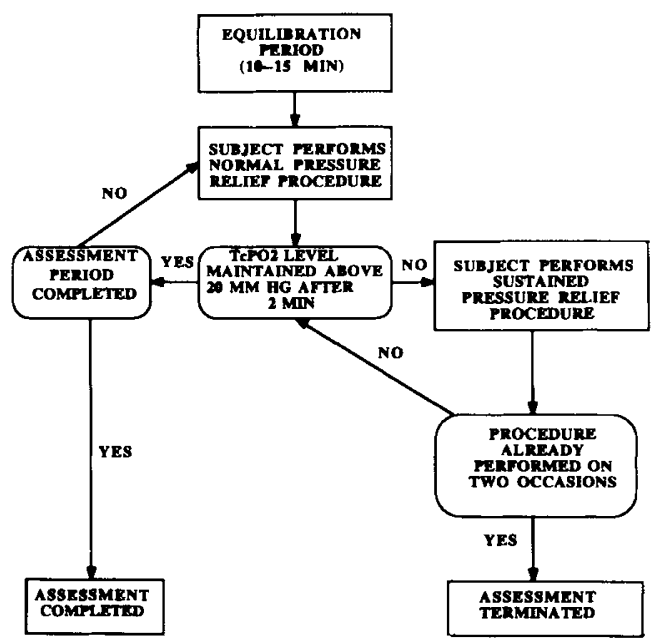

Figure 1 Procedural guidelines for assessment of tissue viability in the seated posture
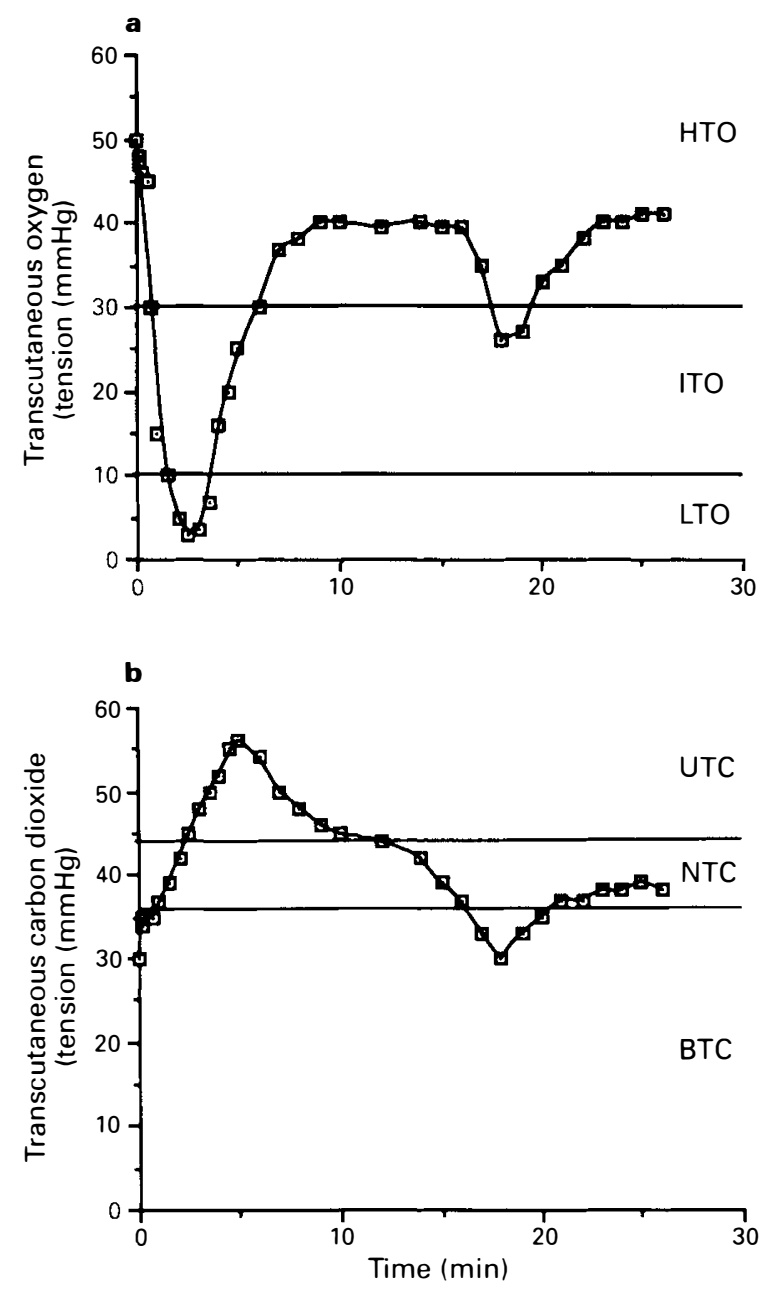

Figure 2 Typical recordings of (a) $\mathrm{T}_{\mathrm{c}} \mathrm{PO}_{2}$ versus time and (b) $\mathrm{T}_{\mathrm{c}} \mathrm{PCO}_{2}$ versus time, with superimposed levels which defined the selected variables of tissue viability

HTO The percentage assessment time that the $\mathrm{T}_{\mathrm{c}} \mathrm{PO}_{2}$ level exceeded $30 \mathrm{mmHg}$

Similarly a distribution of $\mathrm{T}_{\mathrm{c}} \mathrm{PCO}_{2}$ was established, as indicated in Figure 2b, from the three variables:

BTC The percentage assessment time that the $\mathrm{T}_{\mathrm{c}} \mathrm{PCO}_{2}$ level was less than $36 \mathrm{mmHg}$

NTC The percentage assessment time that the $\mathrm{T}_{\mathrm{c}} \mathrm{PCO}_{2}$ level was between $36 \mathrm{mmHg}$ and $44 \mathrm{mmHg}$

UTC The percentage assessment time that the $\mathrm{T}_{\mathrm{c}} \mathrm{PCO}_{2}$ level exceeded $44 \mathrm{mmHg}$

The mean regional interface pressure (IP) measured across the 12 cells, which provides a relative assessment of the pressure profile across the ischium, was determined over the total time for each assessment period. A previous study has indicated that the distribution of interface pressure readings are non-Gaussian in form. ${ }^{6}$ This observation, combined with the nature of the variables describing the state of tissue viability, dictated the use of non-parametric statistical analyses. $P<0.05$ was considered to be statistically significant. 


\section{Results}

An examination of the useage of the cushion types revealed that the Jay cushion was prescribed to subjects with lesions above T6 for longer periods of time than the other cushions during the study. No such difference was observed for subjects with lesions below T6. There were small differences in the distribution of interface pressures measured in either group of subjects, with mean values of approximately $35 \mathrm{mmHg}$ for the three types of prescribed cushions.

The distribution of $\mathrm{T}_{\mathrm{c}} \mathrm{PO}_{2}$ and $\mathrm{T}_{\mathrm{c}} \mathrm{PCO}_{2}$ levels and mean interface pressures were determined for each assessment. The data for all subsequent assessments was then pooled according to the level of lesion, that is above T6 (group I) or below T6 (group II).

The percentage assessment time which the $\mathrm{T}_{\mathrm{c}} \mathrm{PO}_{2}$ levels remained within the lowest defined band, LTO, and the highest defined band, HTO, against time post injury is illustrated in Figures 3 and 4 respectively.
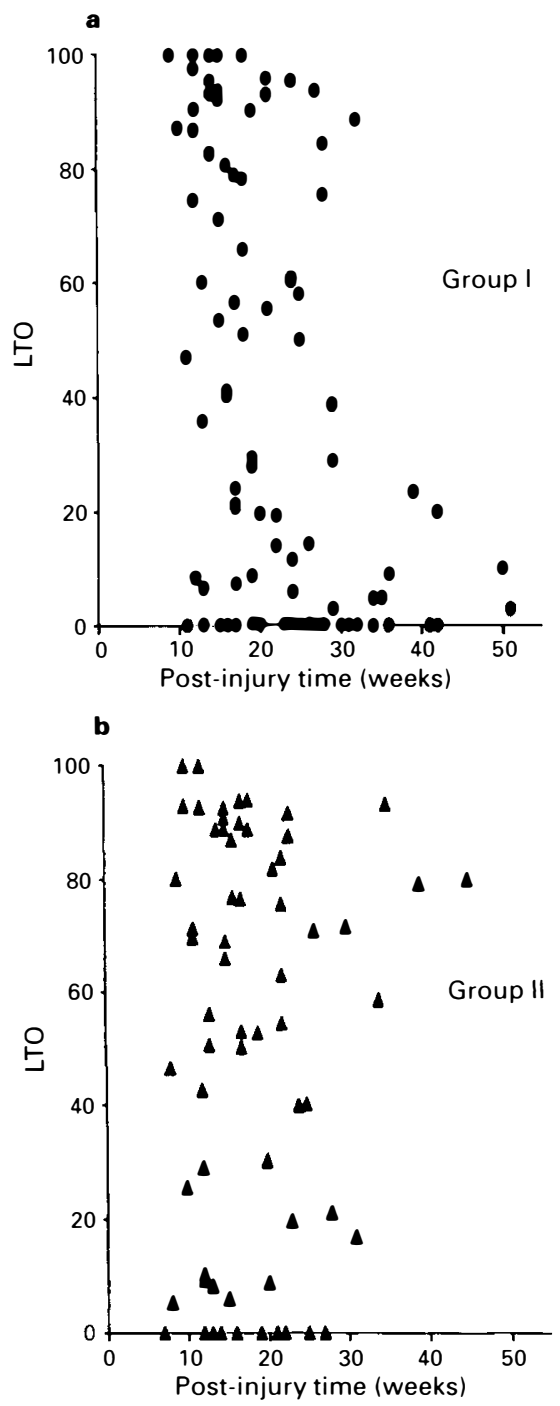

Figure 3 The relationship between assessment time of the variable LTO and the time post injury for (a) subjects with spinal lesions above T6; (b) subjects with spinal lesions below T6
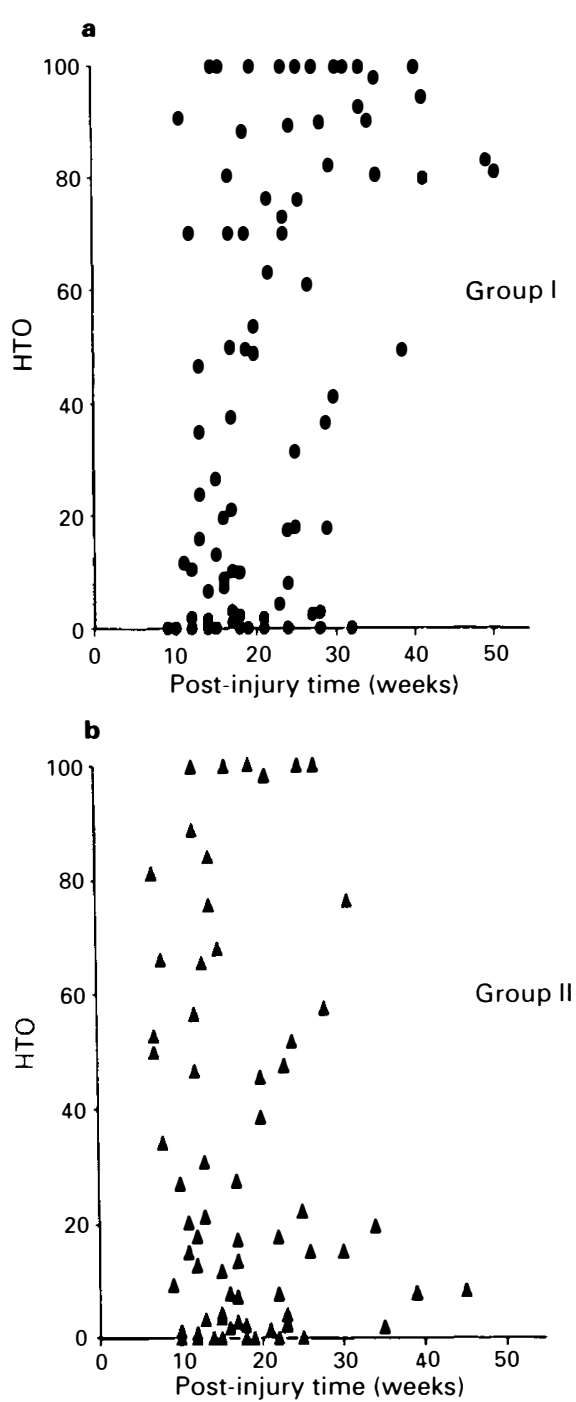

Figure 4 The relationship between assessment time of the variable HTO and the time post injury for (a) subjects with spinal lesions above T6; (b) subjects with spinal lesions below T6

There are clear differences in the trends associated with the two groups of subjects. These trends are also evident when examining a typical response of individual subjects from each group over an extended time period. For example, as illustrated in Figure 5, the $\mathrm{T}_{\mathrm{c}} \mathrm{PO}_{2}$ levels in group I subjects generally exhibited an increased proportion of time spent in HTO, associated with an increase in time spent in NTC, over the assessment period up to 9 months post injury. This was not generally observed with subjects in group II (Figure 6).

There was a considerable variation in the absolute time in weeks post injury at which the assessments were made for each individual subject. However close examination of these times revealed two time periods post injury, ie A (12 \pm 2 weeks) and B ( $24 \pm 2$ weeks), which yielded data for $84 \%$ of the subjects. The statistical tests were restricted to analysis of data from each of these two time periods. 


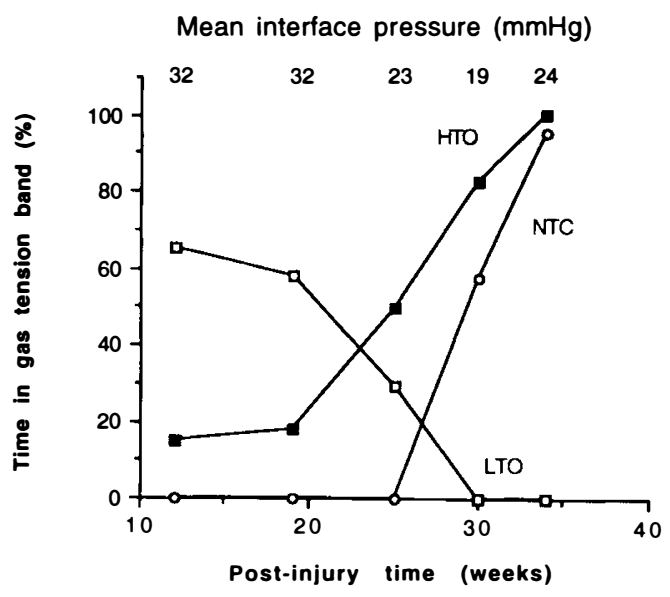

Figure 5 Change of the variables LTO, HTO and NTC with time post injury for a typical group I subject (17-year-old male with a C5 lesion)

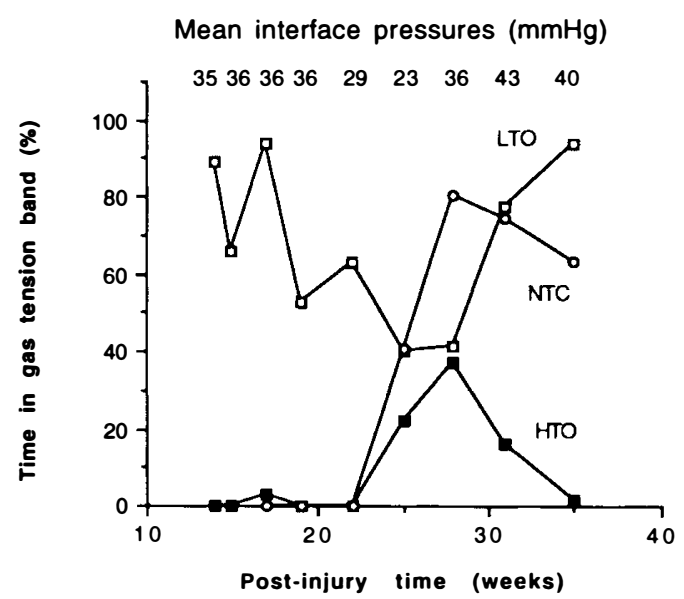

Figure 6 Change of the variables LTO, HTO and NTC with time post injury for a typical group II subject (17-year-old male with a L2 lesion)

The Spearman rank test was applied in order to determine the relationships between experimental tissue variables. Values of the Spearman coefficient, $r_{\mathrm{s}}$, range from +1 to -1 , with a positive value indicating a direct relationship, and a negative value indicating an inverse relationship. Table 2 is a summary of the results of the analyses, which indicated a statistically significant value of $r_{\mathrm{s}}$.

\section{Discussion}

In this paper measurements of transcutaneous gas tensions were performed on the ischial tuberosity of a group of SCI subjects less than 1 year post injury sitting on one of the three prescribed support cushions. The measurements were performed using sensors of $11 \mathrm{~mm}$ diameter which heated the skin in the contact area to ensure maximum vasodilation, because at physiological temperatures the absolute values of $\mathrm{T}_{\mathrm{c}} \mathrm{PO}_{2}$ and $\mathrm{T}_{\mathrm{c}} \mathrm{PCO}_{2}$ are small. It has been shown that at maximum
Early progressive changes in tissue viability in the seated spinal cord injured subject KM Bogie et ol

Table 2 Results of the Spearman rank correlation test indicating the significant relationships between tissue variables

\begin{tabular}{lccc}
\hline $\begin{array}{l}\text { Tissue } \\
\text { variables }\end{array}$ & $\begin{array}{c}\text { Time } \\
\text { period }\end{array}$ & $\begin{array}{c}\text { Spearman } \\
\text { rank } \\
\text { correlation }\end{array}$ & Significance \\
\hline $\begin{array}{l}\text { Group I (above T6) } \\
\text { Mean IP vs LTO }\end{array}$ & B & +0.86 & $P<0.01$ \\
Mean IP vs HTO & B & -0.79 & $P<0.01$ \\
LTO vs NTC & A & -0.77 & $P<0.01$ \\
LTO vs UTC & A & +0.77 & $P<0.01$ \\
ITO vs NTC & A & +0.62 & $P<0.05$ \\
ITO vs UTC & A & -0.60 & $P<0.05$ \\
HTO vs NTC & A & +0.67 & $P<0.05$ \\
HTO vs UTC & A & -0.65 & $P<0.05$ \\
Group II (below T6) & & & \\
Mean IP vs LTO & B & +0.56 & $P<0.05$ \\
Mean IP vs HTO & B & -0.56 & $P<0.05$ \\
LTO vs UTC & B & +0.66 & $P<0.05$ \\
HTO vs UTC & B & -0.81 & $P<0.01$ \\
\hline
\end{tabular}

All other intervariable comparisons were not statistically significant at the $5 \%$ level

Time period $\mathrm{A}=12 \pm 2$ weeks

Time period $\mathrm{B}=24 \pm 2$ weeks

vasodilation $\mathrm{T}_{\mathrm{c}} \mathrm{PO}_{2}$ is equal to arterial oxygen tension. ${ }^{11}$ Although the $\mathrm{T}_{\mathrm{c}} \mathrm{PO}_{2}$ levels were undoubtedly elevated for the subject group, it was the relative changes which were of interest.

Traumatic injury to the spinal cord will initially cause absence of reflex activity below the level of the lesion, known as spinal shock. During this phase, vascular tone is decreased and the applied pressure required to cause occlusion of the blood vessels is reduced, particularly over the bony prominences. Recovery from spinal shock will occur over a highly variable period, from a few days to several months. ${ }^{4}$ In subjects with lesions above T6, reflex function of the isolated spinal cord will return following the spinal shock phase, with a concurrent recovery or even increase in vascular tone, particularly if the autonomic nerve function is also impaired. However in subjects with lesions below T6, diminished or absent reflex function and reduced vascular tone are permanent below the level of the lesion.

The tissue viability, as reflected in $\mathrm{T}_{\mathrm{c}} \mathrm{PO}_{2}$ levels, appears to be different with time for the two groups, as illustrated in Figures 3-6. For subjects with lesions above $\mathrm{T} 6$ there was a reduction with time post injury in low levels of $\mathrm{T}_{\mathrm{c}} \mathrm{PO}_{2}$, ie LTO (Figure 3a), and a corresponding increase in time spent with elevated levels of $\mathrm{T}_{\mathrm{c}} \mathrm{PO}_{2}$ ie $\mathrm{HTO}$ (Figure 4a). By comparison, for subjects with lesions below T6 there was an increase with time of the variable LTO and a corresponding decrease in variable HTO. This finding cannot be attributed to the mean values for interface pressure which did not change significantly. over the rehabilitation phase for either group of subjects. Thus, these results indicate that most subjects with lesions above T6 show a progressive increase in ability to maintain a 
significant transcutaneous oxygen level in ischial tissues under applied loads due to seating. This suggests that tissue viability status improves with time during rehabilitation phase for subjects with higher spinal cord lesions. Conversely, subjects with lesions below T6 are unable to maintain significant transcutaneous oxygen levels under loaded conditions at the seating interface, implying a progressive deterioration in tissue viability status during the rehabilitation phase.

There have been many reports demonstrating that externally applied pressures can compromise tissue viability in the spinal cord injured..$^{5,7,12,13}$ In the present study this has been demonstrated specifically with both groups of subjects in time period B (Table 2). Thus the mean interface pressure (IP) correlated with LTO $\left(r_{\mathrm{r}}(\right.$ group I $)=+0.86 ; r_{\mathrm{s}}($ group II $\left.)=+0.56\right)$ and with HTO $\left(r_{\mathrm{s}}(\right.$ group I $)=-0.79 ; r_{\mathrm{s}}($ group II $\left.)=-0.59\right)$. Although the trends were similar during time period $\mathrm{A}$, the $r_{\mathrm{s}}$ values were not statistically significant.

Correlation between the tissue gas parameters revealed some significant differences (Table 2). For example, the variable UTC correlated significantly with LTO and HTO for group I subjects at time period A, with $r_{\mathrm{s}}$ values of +0.77 and -0.65 respectively. Conversely the variable NTC correlated significantly with LTO and HTO for group I subjects at time period A, with $r_{\mathrm{s}}$ values of -0.77 and +0.67 respectively. Group II subjects indicated fewer significant differences between variables, although at time period B the variable UTC correlated significantly with LTO and HTO. These relationships strongly suggest that the mechanism whereby the level of carbon dioxide is able to control the vascular tone is in operation in the sub-acute SCI subject between about 3 and 9 months post injury. This mechanism was also suggested for the group of acute SCI subjects. ${ }^{10}$ In most cases, the above correlations were greater for subjects with spinal cord lesions above T6, who generally exhibit spastic paralysis. The presence of spasm means that muscle bulk and blood flow are maintained even though useful functional movement is absent. The physical characteristics of the soft tissues in the SCI subject with spastic paralysis are considered to be similar to the normal subject. Therefore, tissue viability under applied loads at the seating interface can generally be maintained. In subjects with spinal cord injuries below T6, two types of lesions can occur; upper motor neuron and lower motor neuron. In the former, the reflex arc is intact and muscles below the level of the lesion retain some tone. Thus muscle bulk and blood flow can be maintained in subjects with upper motor neuron lesions below T6, as they are in subjects with higher level lesions. In lower motor neuron lesions, however, the integrity of the reflex arc is irreversibly disrupted and muscle tone is decreased or absent. This will, in time, lead to muscular atrophy. Thus the subject with a lower motor neuron lesion will exhibit a progressive loss of muscle bulk throughout the rehabilitation phase. These atrophic changes will reduce the amount of soft tissues surrounding the arterial capillary bed and thus increase the effect of the applied pressure. There will be little effect, however, on the venous drainage due to the proliferative potential of the venous system. It is therefore proposed that there is an imbalance between the arterial supply and the venous drainage of the atrophied soft tissues in the paraplegic subject with a lower motor neuron lesion of the spinal cord, which may produce an increase in the clearance rate. In some cases this will be sufficient to cause a decrease in $\mathrm{T}_{\mathrm{c}} \mathrm{PCO}_{2}$ below the normal range, as was observed in this study. The combination of altered vascularity and reduced muscular tone also means that the remaining soft tissues will be more readily compromised in these subjects.

The present findings must be looked at in the light of the clinical observations concerning the incidence of pressure sores in SCI subjects. Noble ${ }^{1}$ reported that tetraplegic patients develop pressure sores less frequently than paraplegics and, of the latter group, it was those with flaccid paralysis who are particularly susceptible to tissue breakdown over the ischial tuberosities. The results of the current study indicate that paraplegics are more likely to have a reduced ability to maintain blood flow when subjected to loads applied during normal sitting on prescribed cushions in a wheelchair.

\section{Conclusions}

This study supports previous reports that paraplegics are at a higher risk of tissue breakdown than tetraplegics. The subjects with spinal cord injury require effective support cushions to maximise the seating contact area and reduce mean interface pressures. A number of other factors, such as temperature and humidity, will also affect the microenvironment at the interface between the subject and support media. Current studies are underway to assess these factors in conjunction with the seating clinic at the National Spinal Injuries Centre, where transcutaneous gas tensions and interface pressures are routinely monitored for all seated SCI subjects at risk. It must always be appreciated that constant vigilance in performing regular pressure relief procedures is of major importance to all SCI subjects, with particular emphasis on those with lower level lesions and flaccid paralysis.

\section{Acknowledgements}

The research post for one of the authors (KB) was supported by a generous grant awarded by the Spinal Amenity Trust Fund, National Spinal Injuries Centre.

\section{References}

1 Noble PC. Prevention of Pressure Sores in Persons with Spinal Cord Injury. World Rehabilitation Fund Inc: New York, 1982, pp 43-55.

2 Shand JEG, McClemont E. Recent advances in the treatment of pressure sores. Paraplegia 1979; 17: 400-406. 
3 Hibbs $P$. The economics of pressure sore prevention. In: Bader DL (ed). Pressure Sores - Clinical Practice and Scientific Approach. Macmillan: London, 1990, pp 35-42.

4 Guttmann L. Spinal Cord Injuries; Comprehensive Management and Research. 2nd edn. Blackwell: London, 1976, p 244.

5 Bader DL. The recovery characteristics of soft tissue following repeated loading. J Rehabil Res Dev 1990; 27: 141-150.

6 Bader DL, Hawken MB. Pressure distribution under the ischium of normal subjects. J Biomed Eng 1986; 8: 353-357.

7 Seiler WO, Stahelin HB. Skin oxygen tension as a function of imposed skin pressure; implication for decubitus ulcer formation. J Am Geriatr Soc 1979; 27: 298-301.

8 Bader DL, Gant CA. Effects of prolonged loading on tissue oxygen levels. In: Spence VA, Sheldon CD (eds). Practical Aspects of Skin Blood Flow Measurements. Biological Engineer- ing Society: London, 1985.

9 Bader DL, Gant CA. Changes in transcutaneous oxygen tension as a result of prolonged pressures at the sacrum. Clin Phys Physiol Meas 1988; 9: 33-40.

10 Bogie KM, Nuseibeh I, Bader DL. Transcutaneous gas tensions in the sacrum during the acute phase of spinal cord injury. Eng Med 1992; 206: 1-6.

11 Keller HP, Klaue $\mathrm{P}$, Lubbers DW. Transcutaneous $\mathrm{PO}_{2}$ measurement for evaluating the oxygen supply of skin allo- and autografts. Eur Surg Res 1978; 11: 272-282.

12 Schubert V, Fagrell B. Postocclusive reactive hyperaemia and thermal response in the skin microcirculation of subjects with spinal cord injury. Scand J Rehabil Med 1991; 23: 33-45.

13 Bennett $\mathrm{L}$ et al. Skin stress and blood pressure flow in sitting paraplegic patients. Arch Phys Med Rehabil 1984; 65: 186-190. 